\title{
The effect of print speed on surface roughness and density uniformity of parts produced using binder jet 3d printing
}

\author{
K. Myers ${ }^{1}$, A. Paterson ${ }^{1}$, T. Iizuka ${ }^{2}$, and A. Klein ${ }^{1}$ \\ ${ }^{1}$ The ExOne Company, 127 Industry Boulevard, North Huntingdon, PA, 15642 \\ ${ }^{2}$ ExOne KK, 161-5 Haneo, Odawara-shi, Kanagawa Japan, 256-0804
}

\begin{abstract}
$\underline{\text { Abstract }}$
One of the main benefits of binder jetting is the ability to print quickly compared to other metal additive manufacturing methods. Demand for higher throughput continues to increase, but the effects of faster print speeds on part outcomes are not yet clearly understood. MIM powders are used to achieve optimal density and surface finish. Printing at slower speeds results in densities near $98 \%$ and average surface roughness values as low as $4 \mu \mathrm{m}(\mathrm{Ra})$, in the as-sintered condition. In this study, spread speeds were varied in order to understand the effect of print speed on surface roughness. 316L D90 -22 $\mu$ m powder was used to print with 3 different spread speeds, 2 different layer thicknesses, and 2 different printhead droplet sizes. The surface finish and density were quantified for the sintered parts that were oriented at $0,22.5$, and 45 degrees with respect to the Zdirection.
\end{abstract}

\section{Keywords:}

Additive Manufacturing, Binder Jetting.

\section{Introduction}

Binder jet additive manufacturing is a powder-based technique that uses an inkjet printhead to selectively deposit binder to form a desired 3D shape. Binder jetting closely resembles powder manufacturing and injection molding techniques in the sense that a green body is formed with a combination of binder and powder, which subsequently undergoes a debinding and sintering process to create a fully dense final part. Compared to laser or electron beam metal additive manufacturing techniques, binder jetting has the highest potential to be competitive for large volume production. This is due to relatively quick printing times and the ability to post-process many parts in large batch furnaces or continuous feeding furnaces, in much the same way as metal injection molding (MIM). The time required to print a part via binder jetting is the sum of four key processes: powder dispensing, powder spreading, binder dispensing, and binder drying. While the layer thickness of the print can also affect printing time, thickness is typically determined by a relationship of approximately $2 \mathrm{x}$ the largest particle size in the distribution [1].

Past work has documented the difficulties of printing with powders smaller than $5 \mu \mathrm{m}$ while using older spreading and dispensing techniques. Most commonly, large porosity was found in parts due to improper spreading of powder, resulting in lower overall mechanical strength for 
the part [2]. This is commonly caused by van der Waals cohesion forces in fine powders [3]. The printing time (the time it takes to dispense binder droplets) can be decreased by either increasing the number of printing modules in the machine itself, or by increasing the speed at which the printhead traverses across the bed. However, increasing the printhead traverse speed cannegatively affect the feature resolution and dimensional accuracy [4]. For powder spreading, the amount of powder that is dispensed and used for spreading directly affects the green density and uniformity of the printed parts. For example, higher amounts of powder in front of the roller can result in higher green densities [5-6]. Drying time is a function of both the amount of binder (saturation) that is deposited each layer as well as the binder's composition. Not allowing enough time for binder dispersion and drying can lead to lower green body strengths [7]. Additionally, not allowing enough time for liquid component of the binder to evaporate can lead to smearing of the part, creating rougher surface finishes and dimensional inaccuracy.

There are only a few literature articles on the impact of spreading speed on green density and powder packing consistency. Studies have found that slower spreading speeds have produced the highest green densities [7-8]. In both studies, a spread speed of 6 or $10 \mathrm{~mm} / \mathrm{sec}$ was the highest speed chosen, respectively. In other studies, Mostafaei et al. used a spread speed of $15 \mathrm{~mm} / \mathrm{sec}$ to print Inconel 625 [9], and Nandwana et al. reports that using a spread speed over $4 \mathrm{~mm} / \mathrm{sec}$ when printing Inconel 718 would lead to non-uniform spreading and delamination [10]. Typically, the powder spreading speed has the largest impact on determining the time to print one layer, with a typical spreading speed of $5 \mathrm{~mm} / \mathrm{sec}$ or slower for particle size distributions similar to $-22 \mu \mathrm{m}$. The average layer time for the ExOne Innovent+ system is 75 seconds when spreading powder at 3 $\mathrm{mm} / \mathrm{sec}$. With this set of parameters, $29 \%$ of the layer time is from spreading powder. That percentage is much higher when using larger build envelopes, like the X125Pro andMFlex.

In a production environment, consistency is crucial to reliably making parts with close tolerances. Such factors as machine wear, machine cleanliness, the number of times powder is recycled, and humidity in the air can alter the flow rate and flow consistency out of the hopper during powder dispensing. Being able to precisely control the amount of powder that is being spread is the key to consistency in green body density. Figure 1 is a schematic of ExOne's Advanced Compaction Technology $\left(\mathrm{ACT}^{\mathrm{TM}}\right)$, developed by ExOne (patent pending), for powder spreading, where LT is the layer thickness, RT is the roughing powder thickness, CR is the compaction ratio, $W_{S}$ is the rotational speed of the smooth roller, $W_{R}$ is the rotational speed of the roughing roller, and $v$ is the spread speed. As mentioned before, the counter rotating roller mechanism of spreading powder has been shown to result in packing densities that are dependent on the amount of powder in front of roller. The ACT works by using a roughing roller ahead of a smooth roller that removes or "cuts" the loose powder layer to a known height and packing density, and has minimal effect on compaction. Preliminary results have shown that the roughing nature of the roller allows the packing density of the powder to be unaffected by the mass of powder that is in front of the roller. This demonstrates that the powder layer created by the roughing roller will be consistent, as long as enough powder is dispensed to the height of LT + RT. 


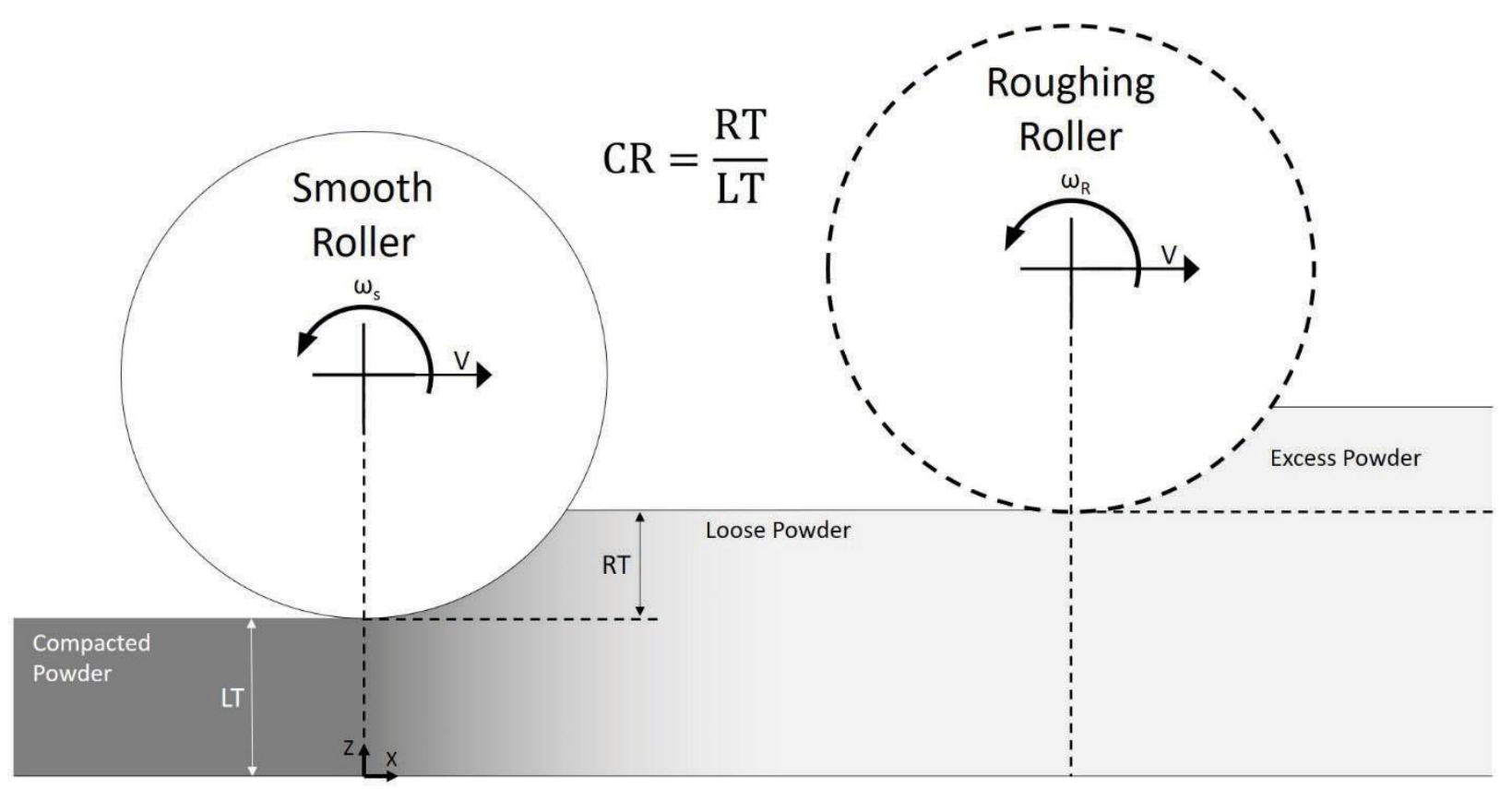

Figure 1 - Schematic of the advanced compaction technology used during the powder spreading process.

This research was performed in order to investigate how the powder spread speed using the ACT affects the green body density as well as the surface roughness of the sintered part. The impact of layer thickness and droplet size on surface roughness was also investigated.

\section{Experimental}

A $90 \%-22 \mu \mathrm{m} 316 \mathrm{~L}$ powder was used during this testing. The particle size distribution was determined to be a $\mathrm{d} 90$ of $15.6 \mu \mathrm{m}$, a d50 of $7.6 \mu \mathrm{m}$, and a d10 of $3.5 \mu \mathrm{m}$. The particle size was determined by a Shimadzu SALD-3001 laser diffraction particle size analyzer. All parts were printed on an ExOne Innovent+ binder jet printer using the ExOne solvent binder at $70 \%$ saturation, a smooth roller rotational speed and a roughing roller rotational speed were held constant, and a compaction ratio of 2 . The layer thickness and droplet size were tested with the combination of either a $50 \mu \mathrm{m}$ layer thickness with a $30 \mathrm{pL}$ droplet or a $30 \mu \mathrm{m}$ layer thickness with a $10 \mathrm{pL}$ droplet. The roller height difference for the Advanced Compaction Technology was set at $100 \mu \mathrm{m} .15$ coupons $(25.4$ × 25.4 x $6.35 \mathrm{~mm})$ were printed in each trial. Of those, 5 coupons each were printed at angles of 0, 22.5, and 45 degrees in relationship to the Z-direction (see Figure 2). After printing, all samples were cured for 8 hours at $200^{\circ} \mathrm{C}$ in air. Following the curing stage, the coupons were depowdered and physically measured with calipers and weighed to obtain density measurements. 


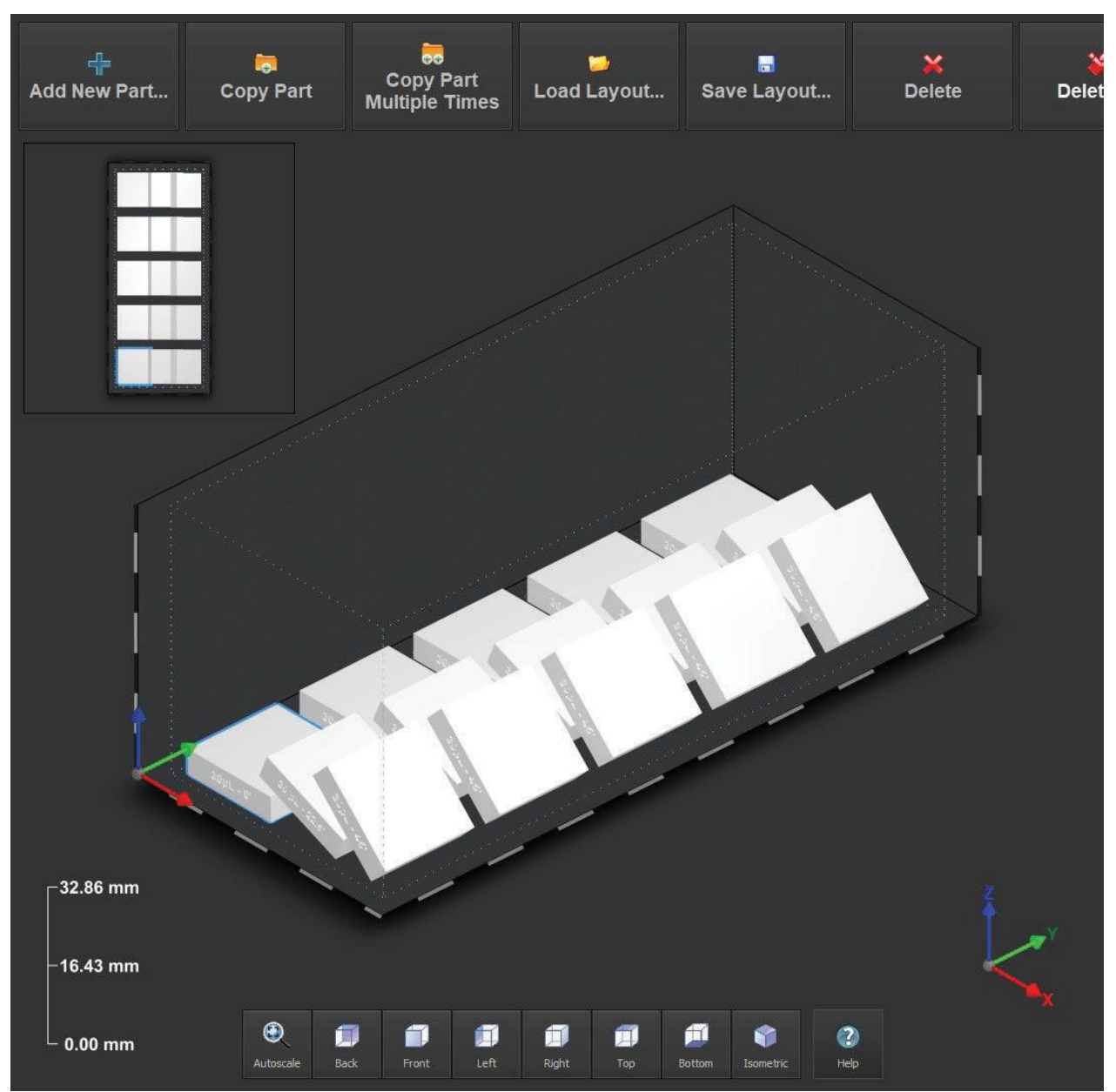

Figure 2 - The build layout of each trial as shown in the Innovent+ software.

All coupons were sintered in a graphite hot zone furnace with partial pressure hydrogen to a temperature of $1380^{\circ} \mathrm{C}$. After sintering, the coupons were once again physically measured with calipers and weighed for density calculations. The surface roughness of each coupon was measured 5 times with a Phase II portable surface roughness gauge, which has a diamond stylus that is accurate to $0.001 \mu \mathrm{m}$. A length of $1 \mathrm{~mm}$ was sampled in each test in accordance with Figure 3 . 
a)

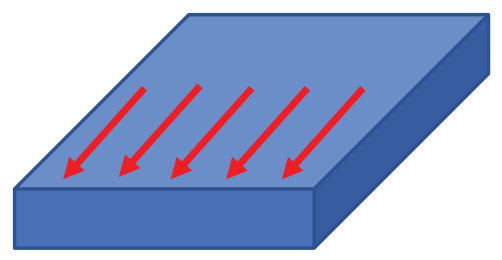

Layer Thickness

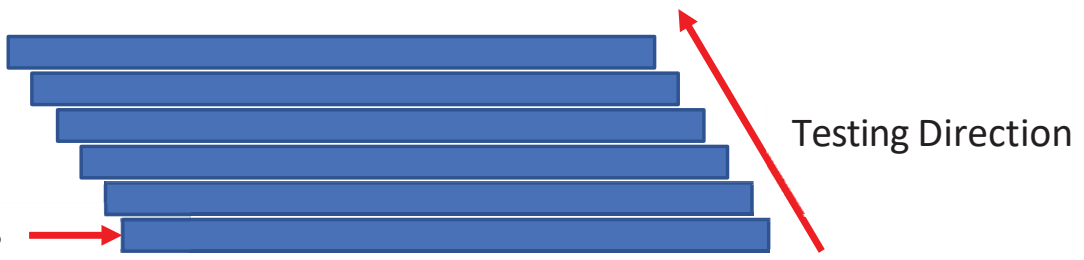

Figure 3 - a) Schematic of a coupon being tested 5 times in various positions across the surface of the coupon and b) schematic of the stylus traverse direction against layer thickness of angled coupons.

The surface roughness of one coupon from each of the printing conditions was also tested with a Keyence VX-6000 light microscope in a 3D plot of the topology. The 3D topology scan was performed across a $12.5 \times 2.5 \mathrm{~mm}$ plane on the top surface of the coupons. The microscope scanned a rate of $0.3 \mathrm{~mm} / \mathrm{sec}$ at $500 \mathrm{x}$ magnification.

\section{Results and Discussion}

The green and sintered density values from all six printing trials can be seen in Table 1 . Table 1 shows that in all trials, when the powder spread speed is increased, the standard deviation of the density increases. This demonstrates that the slowest spreading speed allows for the most consistent powder packing density. The average green density decreased with the larger layer thickness of $50 \mu \mathrm{m}$, but stays relatively consistent with increased powder spreading speed. Similar to MIM, a higher degree of consistency in green body density creates consistent and repeatable shrinkage during sintering. Although the coupons with the $50 \mu \mathrm{m}$ layer thickness have a lower average green density than the $30 \mu \mathrm{m}$ layer thickness, the coupons were able to sinter to over $98 \%$ dense.

When evaluating the effect coupon angle has on green density, the average density decreases with increased coupon angle (see Table 2). This is consistent with literature which has found that porosity in the green state of binder jetted parts is mostly found between the conjoining layer thicknesses due to particle ejection from the impact of the droplets [11]. This porosity effect can also manifest in the sintered stage, showing lines of porosity in the Z-direction [12]. The porosity increases in the angled coupons due to the increasing the number of layers needed to print these parts. Figure 4 shows a plot of the green body density with respect to the couponangle. 
Table 1 - The average green and sintered densities of each trial. Theoretical density used is $7.99 \mathrm{~g} / \mathrm{cc}$.

\begin{tabular}{|c|c|c|c|c|c|c|c|}
\hline Trial & Droplet & Layer & $\begin{array}{c}\text { Spread } \\
\text { Speed }\end{array}$ & $\begin{array}{c}\text { Green } \\
\text { Density }\end{array}$ & $\begin{array}{c}\text { GD } \\
\text { St.Dev. }\end{array}$ & $\begin{array}{c}\text { Sintered } \\
\text { Density }\end{array}$ & $\begin{array}{c}\text { SD } \\
\text { St.Dev. }\end{array}$ \\
\hline$\#$ & $\mathrm{pL}$ & $\mu \mathrm{m}$ & $\mathrm{mm} / \mathrm{sec}$ & $\%$ & $\%$ & $\%$ & $\%$ \\
\hline 1 & 30 & 50 & 3 & 52.67 & 0.52 & 98.22 & 0.41 \\
\hline 2 & 30 & 50 & 50 & 52.25 & 1.09 & 98.17 & 0.49 \\
\hline 3 & 30 & 50 & 125 & 49.99 & 0.86 & 98.49 & 0.34 \\
\hline 4 & 10 & 30 & 3 & 53.50 & 0.42 & 98.93 & 0.45 \\
\hline 5 & 10 & 30 & 50 & 54.04 & 1.38 & 98.80 & 0.93 \\
\hline 6 & 10 & 30 & 125 & 54.90 & 2.71 & 97.51 & 0.77 \\
\hline
\end{tabular}

Table 2 - The average coupon green densities from each trial.

\begin{tabular}{|c|c|c|c|c|c|}
\hline Trial & $\begin{array}{c}\text { Spread } \\
\text { Speed }\end{array}$ & Printhead & Angle & $\begin{array}{c}\text { Average } \\
\text { Density }\end{array}$ & St. Dev. \\
\hline$\#$ & $\mathrm{~mm} / \mathrm{sec}$ & $\mathrm{pL}$ & $\circ$ & $\%$ & $\%$ \\
\hline 1 & 3 & 30 & 0 & 53.32 & 0.11 \\
\hline 1 & 3 & 30 & 22.5 & 52.52 & 0.28 \\
\hline 1 & 3 & 30 & 45 & 52.18 & 0.25 \\
\hline 2 & 50 & 30 & 0 & 53.41 & 1.34 \\
\hline 2 & 50 & 30 & 22.5 & 51.69 & 0.41 \\
\hline 2 & 50 & 30 & 45 & 51.66 & 0.17 \\
\hline 3 & 125 & 30 & 0 & 51.01 & 0.42 \\
\hline 3 & 125 & 30 & 22.5 & 49.92 & 0.37 \\
\hline 3 & 125 & 30 & 45 & 49.05 & 0.30 \\
\hline 4 & 3 & 10 & 0 & 53.73 & 0.22 \\
\hline 4 & 3 & 10 & 22.5 & 53.64 & 0.23 \\
\hline 4 & 3 & 10 & 45 & 53.13 & 0.54 \\
\hline 5 & 50 & 10 & 0 & 54.87 & 1.77 \\
\hline 5 & 50 & 10 & 22.5 & 53.43 & 1.18 \\
\hline 5 & 50 & 10 & 45 & 53.83 & 1.13 \\
\hline 6 & 125 & 10 & 0 & 57.92 & 0.78 \\
\hline 6 & 125 & 10 & 22.5 & 54.24 & 2.82 \\
\hline 6 & 125 & 10 & 45 & 52.55 & 0.29 \\
\hline
\end{tabular}




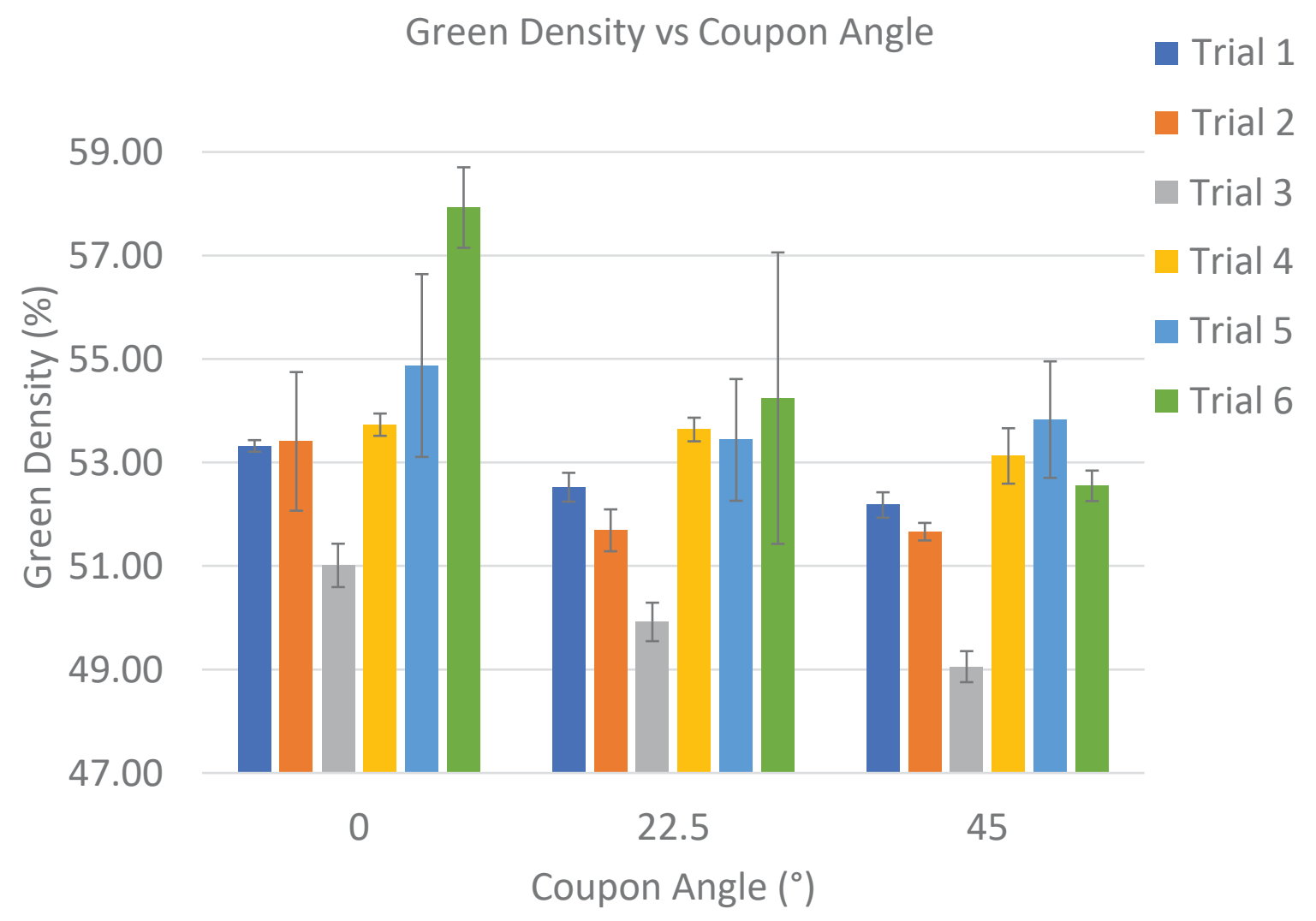

Figure 4 - The average green density profile for each Trial in respect to coupon print
angle.

The surface finish data from the Phase II surface roughness gauge can be seen in Table 3 and are plotted in Figures 5 and 6. The data shows that in the case of both the $10 \mathrm{pL}$ and $30 \mathrm{pL}$ printhead trials, the surface roughness $(\mathrm{Ra})$ increases with both spread speed and coupon angle. The averages of all of the trials showed that the lowest surface roughness ( $\mathrm{Ra}$ ) was $4.05 \mu \mathrm{m}$, and was found on the sample printed at $0^{\circ}$ from the horizontal with a $30 \mathrm{pL}$ printhead and a $50 \mu \mathrm{m}$ layer thickness. The highest Ra value was $9.78 \mu \mathrm{m}$, which was printed with a $30 \mathrm{pL}$ printhead and $50 \mu \mathrm{m}$ layer thickness. The data shows that Ra value approaches a plateau between 50 and 125 $\mathrm{mm} / \mathrm{sec}$ spread speed. The data from the Keyence microscope is in agreement with the data found from the Phase II roughness gauge, showing the same trends for increased surface roughness with spread speed and angle. The plots of the surface roughness found with the Keyence microscope can be seen in Figures 7 and 8. The surface roughness values are also in agreement with literature values of sintered parts with similar particle size distributions $[9,13]$. A topology map of the $10 \mathrm{pL}$ sample printed at 0 degrees and $3 \mathrm{~mm} / \mathrm{sec}$ taken with the Keyence microscope at 100x magnification can be seen in Figure 9. The topology map shows uniform surface with typical hills and valleys, with no unique surface topology defects or spikes. 
Table 3 - The average coupon surface roughness values of each trial, taken from the Phase II analyzer.

\begin{tabular}{|c|c|c|c|c|c|}
\hline Trial & $\begin{array}{c}\text { Spread } \\
\text { Speed }\end{array}$ & Printhead & Angle & $\begin{array}{c}\text { Average } \\
\text { Ra }\end{array}$ & $\begin{array}{c}\text { St. } \\
\text { Dev. }\end{array}$ \\
\hline$\#$ & $\mathrm{~mm} / \mathrm{sec}$ & $\mathrm{pL}$ & $\circ$ & $\mu \mathrm{m}$ & $\mu \mathrm{m}$ \\
\hline 1 & 3 & 30 & 0 & 4.05 & 0.55 \\
\hline 1 & 3 & 30 & 22.5 & 7.66 & 0.47 \\
\hline 1 & 3 & 30 & 45 & 7.27 & 0.66 \\
\hline 2 & 50 & 30 & 0 & 5.43 & 0.61 \\
\hline 2 & 50 & 30 & 22.5 & 9.50 & 0.58 \\
\hline 2 & 50 & 30 & 45 & 9.42 & 0.96 \\
\hline 3 & 125 & 30 & 0 & 6.40 & 0.53 \\
\hline 3 & 125 & 30 & 22.5 & 9.78 & 0.68 \\
\hline 3 & 125 & 30 & 45 & 9.20 & 0.53 \\
\hline 4 & 3 & 10 & 0 & 5.02 & 0.42 \\
\hline 4 & 3 & 10 & 22.5 & 6.70 & 0.61 \\
\hline 4 & 3 & 10 & 45 & 7.27 & 0.80 \\
\hline 5 & 50 & 10 & 0 & 5.58 & 0.49 \\
\hline 5 & 50 & 10 & 22.5 & 7.86 & 0.69 \\
\hline 5 & 50 & 10 & 45 & 7.86 & 0.67 \\
\hline 6 & 125 & 10 & 0 & 5.02 & 0.67 \\
\hline 6 & 125 & 10 & 22.5 & 7.21 & 0.84 \\
\hline 6 & 125 & 10 & 45 & 7.87 & 0.79 \\
\hline
\end{tabular}




\section{Roughness vs Print Speed 30pl}

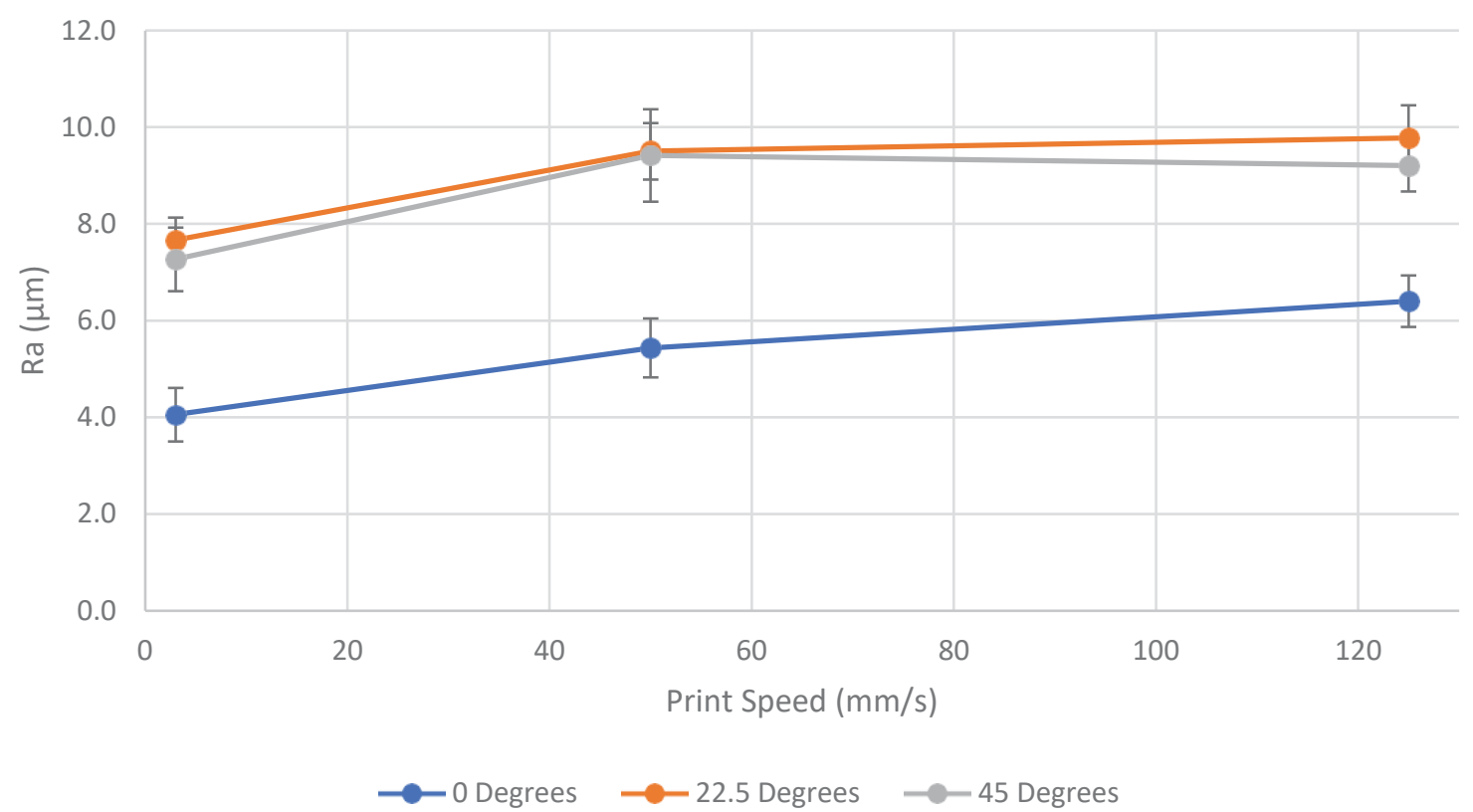

Figure 5 - Plot of surface roughness as a function of spread speed for the $30 \mathrm{pL}$ Trials taken with the Phase II analyzer.

Roughness vs Print Speed 10pl

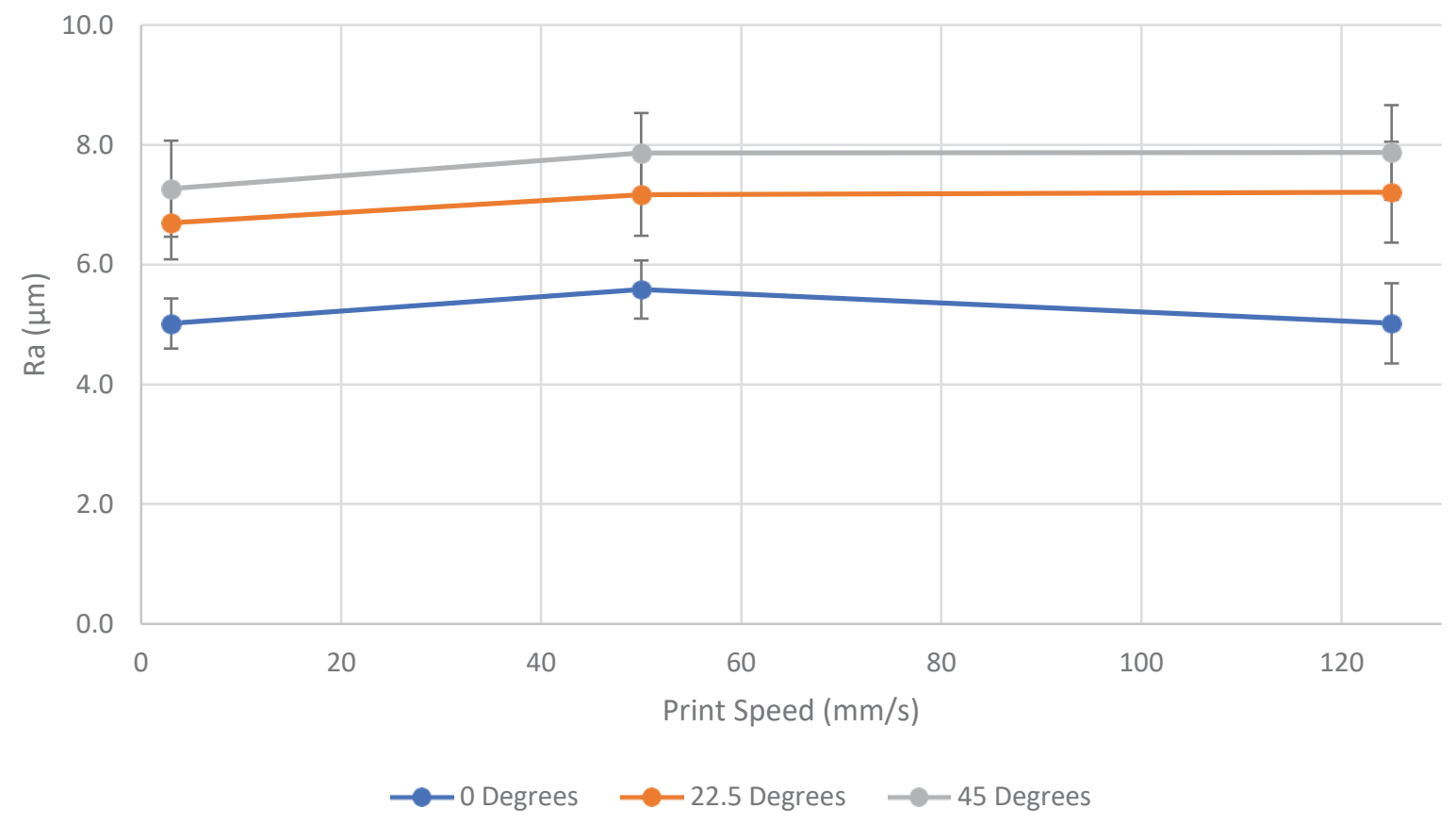

Figure 6 - Plot of surface roughness as a function of spread speed for the $10 \mathrm{pL}$ Trials taken with the Phase II analyzer. 


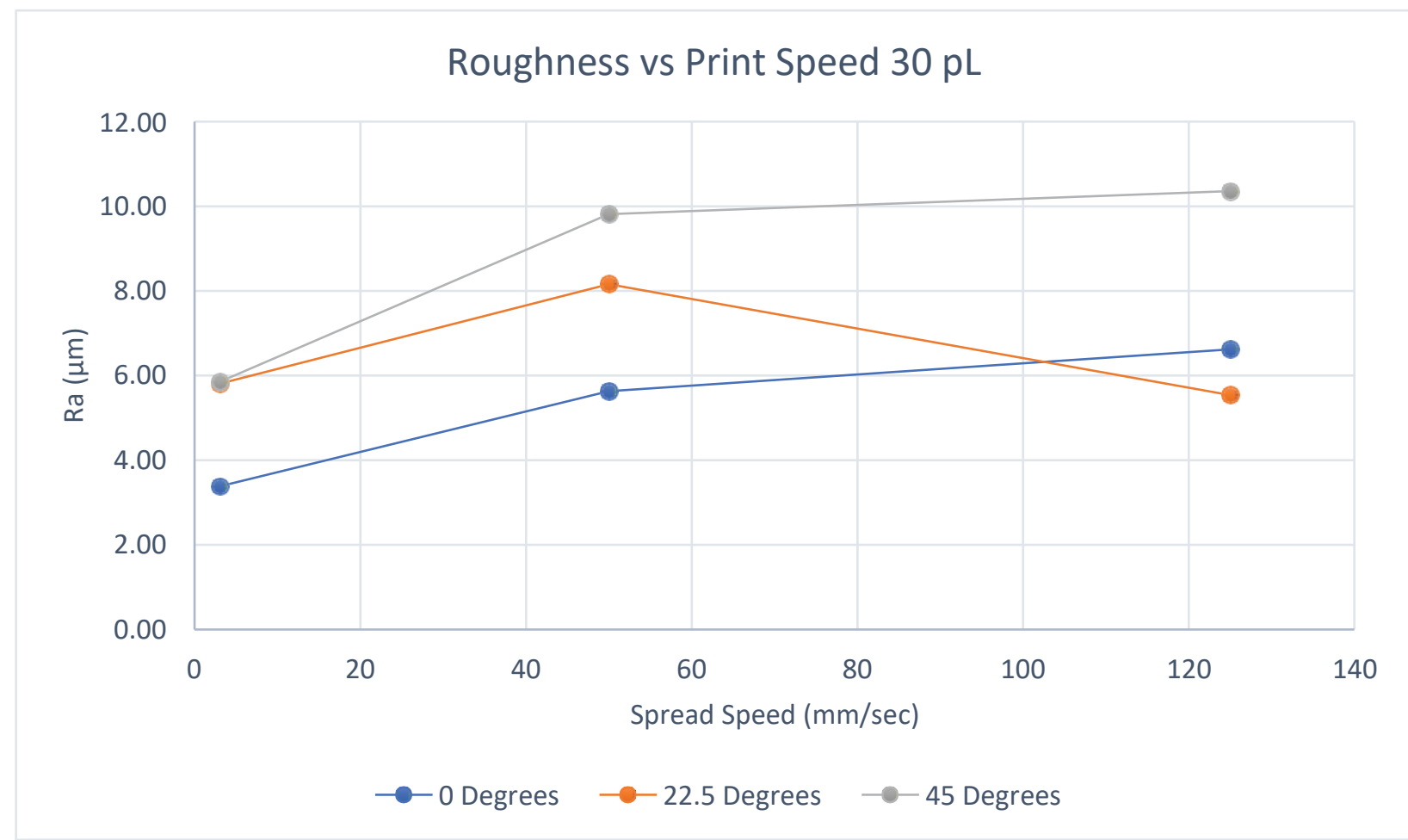

Figure 7 - Plot of surface roughness as a function of spread speed for the $30 \mathrm{pL}$ Trials taken with the Keyence microscope.

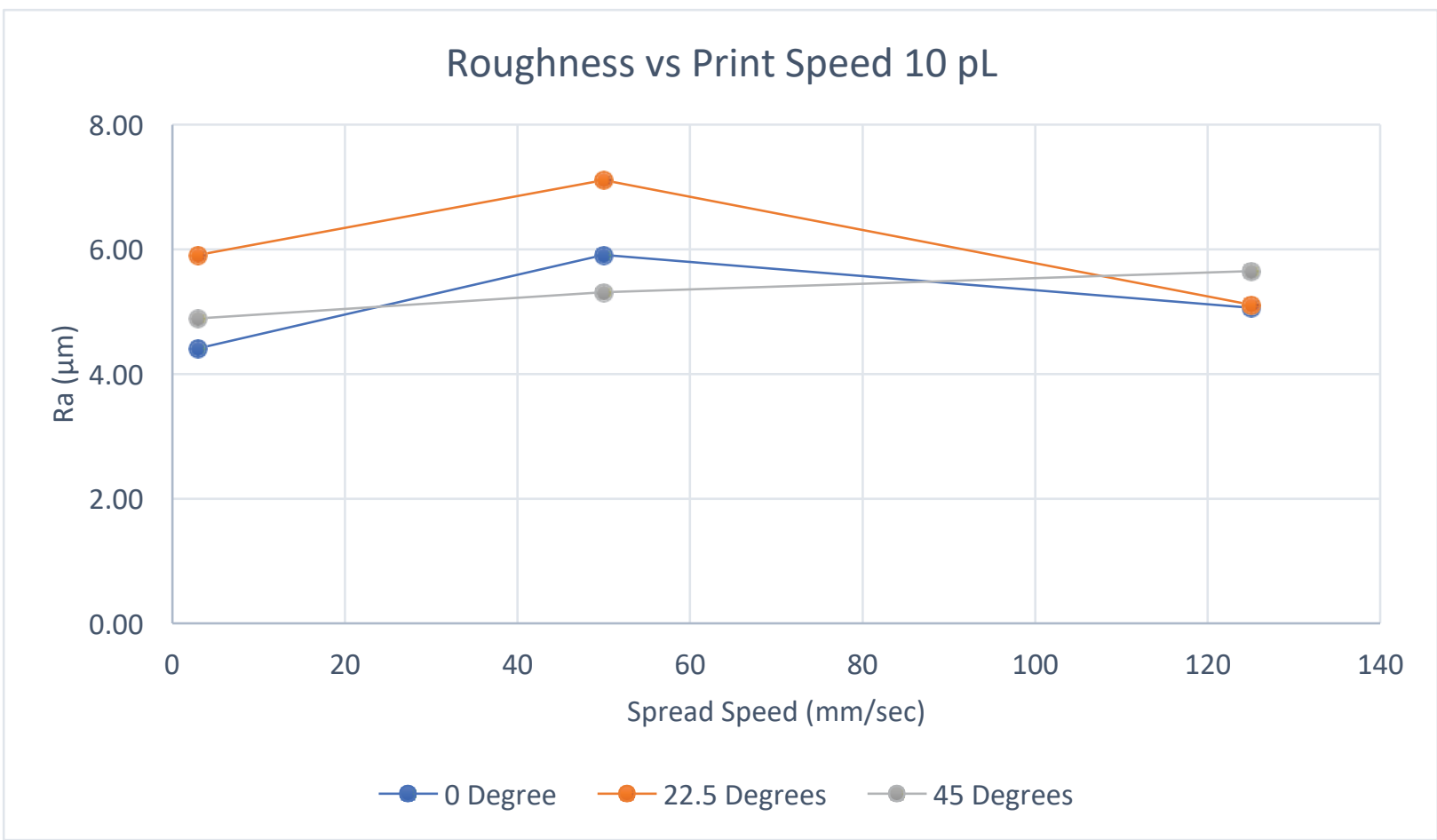

Figure 8 - Plot of surface roughness as a function of spread speed for the $10 \mathrm{pL}$ Trials taken with the Keyence microscope. 


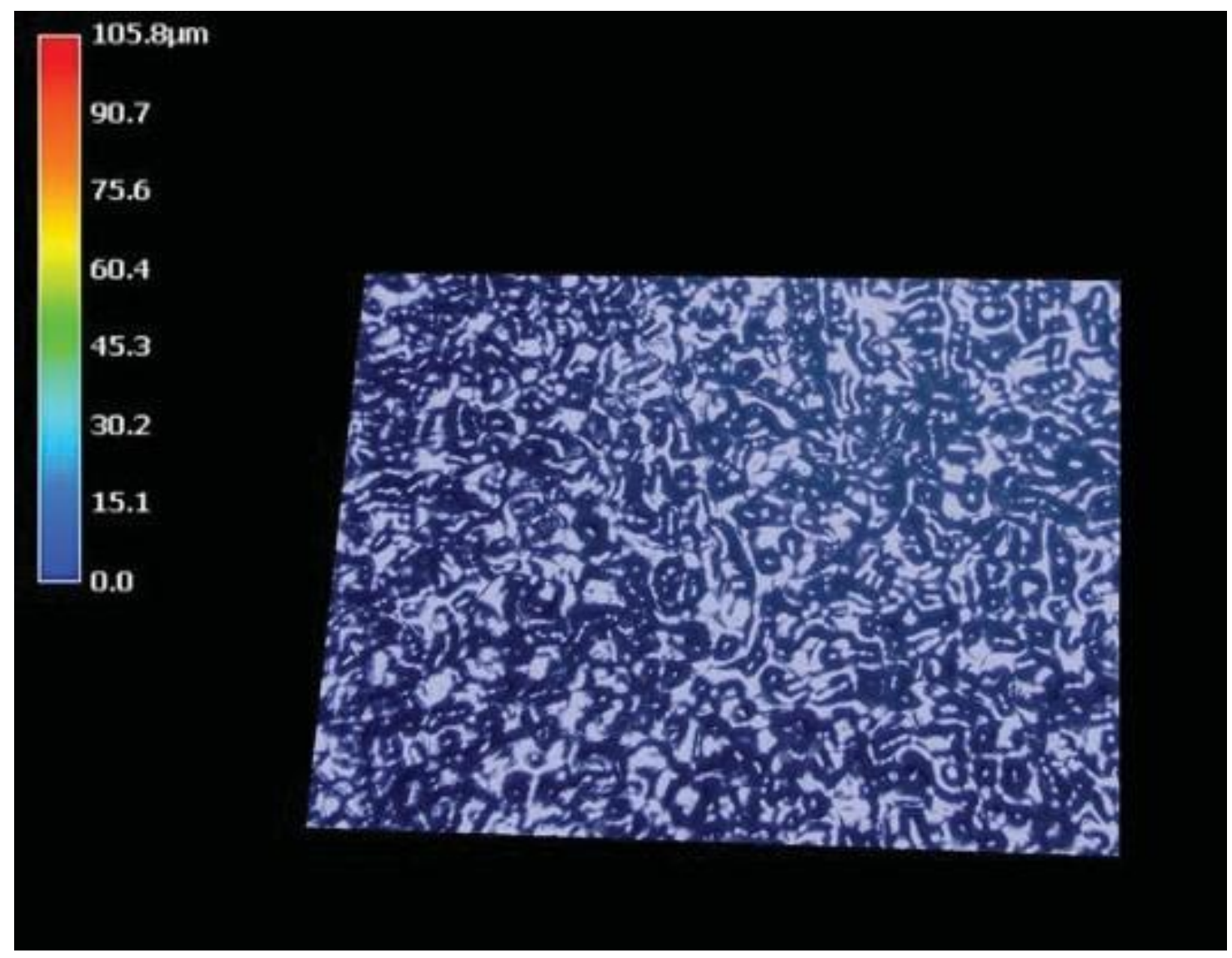

Figure 9 - Surface topology of the $10 \mathrm{pL}$ sample printed at 0 degrees and $3 \mathrm{~mm} / \mathrm{sec}$ taken with the Keyence microscope at 100x magnification.

\section{Conclusions}

The green body density, sintered density, and surface roughness profile were characterized realtive to spread speed and part angle. The relationships were characterized for the combination of a $50 \mu \mathrm{m}$ layer thickness and $30 \mathrm{pL}$ printhead, and a $30 \mu \mathrm{m}$ layer thickness and $10 \mathrm{pL}$ printhead. The results of the testing are the following:

- The average green body density decreases and the standard deviation increases with increasing spread speeds. The average density did not decrease with spread speed with the $30 \mu \mathrm{m}$ layer thickness and $10 \mathrm{pL}$ printhead, but the standard deviation increased.

- The average green body density was slightly higher with the $30 \mu \mathrm{m}$ layer thickness (54\%), than the $50 \mu \mathrm{m}$ layer thickness (50-52\%).

- The average green body density decreases slightly with increasing coupon orientation angle in relationship to the Z-direction.

- Although there is a deviation in green body densities from various process settings, all coupons sintered to an average green body density of $97.5 \%$ theoretical or higher.

- The surface roughness ( $\mathrm{Ra}$ ) typically increases with faster spreading speeds and increased coupon orientation angle. 
- The smallest average surface roughness value $(\mathrm{Ra})$ was found to be $4.05 \mu \mathrm{m}$ with the 50 $\mu \mathrm{m}$ layer thickness and $30 \mathrm{pL}$ printhead on a flat surface with a spread speed of $3 \mathrm{~mm} / \mathrm{sec}$. The largest average roughness $(\mathrm{Ra})$ was found to be $9.78 \mu \mathrm{m}$ with the $50 \mu \mathrm{m}$ layer thickness and $30 \mathrm{pL}$ printhead on a $22.5^{\circ}$ coupon with a $125 \mathrm{~mm} / \mathrm{sec}$ spread speed.

\section{References}

1. Gibson, I., Rosen, D. W., and Stucker, B., 2015, Additive Manufacturing Technologies: 3D Printing, Rapid Prototyping, and Direct Digital manufacturing, 2nd, Springer, New York, pp. 1-498.

2. Miyanaji, H., Zhang, S., Lassell, A., Zandinejad, A. A., \& Yang, L. (2016). Optimal process parameters for 3D printing of porcelain structures. Procedia Manufacturing, 5, 870-887.

3. Sachs, E. M., Cima, M. J., Caradonna, M. A., Grau, J., Serdy, J. G., Saxton, P. C., Uhland, S. A., \& Moon, J. (2003). U.S. Patent No. 6,596,224. Washington, DC: U.S. Patent and Trademark Office.

4. Miyanaji, H., Momenzadeh, N., \& Yang, L. (2018). Effect of printing speed on quality of printed parts in Binder Jetting Process. Additive Manufacturing, 20, 1-10.

5. Shanjani, Y., \& Toyserkani, E. (2008, August). Material spreading and compaction in powder-based solid freeform fabrication methods: mathematical modeling. In 19th Annual International Solid Freeform Fabrication Symposium, SFF (Vol. 2018, pp. 399-410).

6. Shrestha, S., \& Manogharan, G. (2017). Optimization of binder jetting using Taguchi method. Jom, 69(3), 491-497.

7. Miyanaji, H., Zhang, S., Lassell, A., Zandinejad, A., \& Yang, L. (2016). Process development of porcelain ceramic material with binder jetting process for dental applications. Jom, 68(3), 831-841.

8. Myers, K. M. (2016). Structure-Property Relationship of Binder Jetted Fused Silica Preforms to Manufacture Ceramic-Metallic Interpenetrating Phase Composites. (Doctoral dissertation, Youngstown State University).

9. Mostafaei, A., Neelapu, S. H. V. R., Kisailus, C., Nath, L. M., Jacobs, T. D., \& Chmielus, M. (2018). Characterizing surface finish and fatigue behavior in binder-jet 3D-printed nickel-based superalloy 625. Additive Manufacturing, 24, 200-209.

10. Nandwana, P., Elliott, A. M., Siddel, D., Merriman, A., Peter, W. H., \& Babu, S. S. (2017). Powder bed binder jet 3D printing of Inconel 718: Densification, microstructural evolution and challenges. Current Opinion in Solid State and Materials Science, 21(4), 207-218.

11. Parab, N. D., Barnes, J. E., Zhao, C., Cunningham, R. W., Fezzaa, K., Rollett, A. D., \& Sun, T. (2019). Real time observation of binder jetting printing process using high-speed X-ray imaging. Scientific reports, 9(1), 2499.

12. Mostafaei, A., De Vecchis, P. R., Nettleship, I., \& Chmielus, M. (2019). Effect of powder size distribution on densification and microstructural evolution of binder-jet 3D-printed alloy 625. Materials \& Design, 162, 375-383.

13. Miyanaji, H. (2018). Binder jetting additive manufacturing process fundamentals and the resultant influences on part quality. (Doctoral dissertation, University of Louisville). 